\title{
Cartilla de Puericultura de la Sociedad Chilena de Pediatría
}

Publicado en Rev Chil Pediatr 1930; 1 (4): 213-6

Autor: PUBLICADO POR LA CRUZ ROJA CHILENA DURANTE LA SEMANA DE LA MADRE. 1929 Comentario: LUISA SCHONHAUT B. ${ }^{1}$

1. Profesor Asistente, Magíster Salud Pública, Departamento de Pediatría Norte, Facultad de Medicina, Universidad de Chile.

Palabras clave: Puericultura, pediatría, historia pediatría.

Key words: Pediatrics, pediatric history.

\section{Introducción}

El término pediatría procede del griego: paidos (niño) y iatrea (curación), mientras que puericultura proviene del latín: puerilis (niño) y cultura (cultivo) ${ }^{1}$. Ambos términos unidos resumen el rol del pediatra, quien es el especialista capacitado en proveer una salud integral a los niños y adolescentes a lo largo del proceso de crecimiento y desarrollo, tanto en condiciones de salud como de enfermedad, en el contexto del equipo de salud.

Entre los días 10 y 16 de noviembre de 1929 se llevó a cabo la Semana de la Madre, con el objetivo de hacer una cruzada nacional de divulgación científica y enseñanza sobre puericultura "la tarea fue iniciada bajo los mejores auspicios y como consecuencia suya, ha dado comienzo la protección oficial efectiva de la Madre y del Niño en toda la República, con la creación de la Oficina Central del Niño y el consejo consultivo, idea sustentada desde tanto tiempo atrás por los médicos pediatras y ardientemente auspiciada por el organismo que los reúne: la Sociedad de Pediatría”(Dr. GMB, 1930)².
Con la colaboración de la Cruz Roja Chilena se difundió la Cartilla de Puericultura, la que se trascribe a continuación. Si bien hay algunos aspectos que aparecen como anecdóticos, hay otros completamente actuales y vigentes.

\section{Cartilla de Puericultura de la Sociedad Chilena de Pediatría}

\section{Los padres}

Para tener un hijo sano, los padres deben ser jóvenes y sanos de cuerpo y espíritu.

Si Ud. es sifilítico, tuberculoso, alcohólico o toxicómano (cocaína, morfina, éter, etc), no engendre un hijo antes de haberse puesto en curación. La sífilis, el alcoholismo, la toxicomanía, degeneran la raza y producen en los hijos atraso intelectual, instintos perversos, locuras, epilepsia, etc.

La tuberculosis es contagiosa y el niño en contacto con sus padres tuberculosos o en un ambiente tuberculoso, será fatalmente tuberculoso.

Si Ud. tiene desviaciones del instinto sexual no tenga hijos, porque ellos serán como Ud. unos desgraciados.

Piense en que la felicidad de sus hijos está en que les trasmita una herencia de salud corporal y espiritual mejor que una herencia de dinero o de situación social. 
Si Ud. padece de un mal hereditario como los enumerados antes, y quiere tener hijos sanos, hágase tratamiento médico y evitará así las consecuencias de ese mal para Ud. y para su familia.

\section{EI embarazo}

El niño será tanto más sano cuanto más se cuide la mujer durante el embarazo: vida tranquila, ejercicio moderado, comida sana, pocas fiestas, pocos malos ratos, pocas emociones violentas, poca actividad sexual. Los quehaceres domésticos no perjudican su estado.

Si Ud. es obrera, acuérdese que las leyes sociales dan muchas franquicias a la madre durante el embarazo y en la lactancia: aprovéchelas.

Hágase examinar cada 2 ó 3 meses para ver la situación del feto y si el embarazo marcha bien.

Cuide mucho de su aseo corporal, sobre todo de las partes genitales.

Cuide de su pezón para que cuando mame el niño no tenga grietas (lavado y masaje diario del pezón con alcohol y piedra alumbre).

\section{El niño}

El niño sano debe pesar al nacer más o menos 3500 gramos si es varón y 3 200, si es niña. Debe duplicar su peso a los 6 meses y triplicarlo al año.

Desde que cae el cordón ( $7^{\circ}$ día) debe bañarse todos los días.

Debe dormir siempre sólo y con moderado abrigo.

No pasearlo ni mecerlo para que se duerma.

No darle ni chupetes ni agüitas: la leche materna tiene de sobra la cantidad de líquido que el niño necesita.

Debe mudarse cada vez que se moje, a lo menos 5 ó 6 veces al día antes de alimentarlo: así no tendrá coceduras.

Debe alimentarse a horas fijas en el día: en la noche su estómago descansará por lo menos 7 horas.

Si el niño duerme a la hora de su alimento se le despertará y si llora, antes de su hora, se le enseñará a esperar.

¡El niño necesita mucho aire libre! Nada de encierros. Si el niño pasa al aire libre y en la noche duerme con la ventana ampliamente abierta se robustecerá y no se resfriará sino muy raras veces.

Los dientes salen a los 7 meses y su salida no trae sino ligeras molestias. No descuide la diarrea de su niño creyendo que es debido a la salida de los dientes. Su descuido puede traer la muerte de la criatura.

No emplee en esta época los jarabes calmantes de la dentición porque todos son dañinos.

El niño obra 2 ó 3 veces al día.

La estitiquez, lo mismo que la frecuencia de las deposiciones o el vómito no son enfermedades sino cuando comprometen el desarrollo del niño.

Hay que vacunar al niño al $3^{\circ}$ mes y revacunarlo cada 5 años.

El niño sostiene su cabeza a los 3 meses, se sienta solo a los 6 meses, se mantiene en pie a los 9, comienza a caminar al año y habla a los dos años.

Evite el beso a su niño: el beso como la mosca, es el otro gran enemigo de los pequeñuelos, puede transmitirle las enfermedades más graves, tifus, tuberculosis, disenterías, etc.

\section{El llanto del niño}

El niño llora no sólo por hambre. Generalmente el niño llora:

$1^{\circ}$ Porque está cocido, o sea porque no se le muda lo suficiente.

$2^{\circ}$ Porque está demasiado oprimido por su ropa o porque tiene demasiado abrigo.

$3^{\circ}$ Porque come poco; porque come demasiado; porque come a horas desordenadas. Pese Ud. a su niño cada semana y verá si aumenta de peso o disminuye y sabrá si come poco o come lo suficiente.

$4^{\circ}$ Porque es nervioso o está enfermo (hernias, deformaciones del esqueleto, sífilis, etc).

\section{El niño está sano}

$1^{\circ} \mathrm{Si}$ duerme bien.

$2^{\circ} \mathrm{Si}$ aumenta de peso y de estatura, normalmente.

$3^{\circ}$ Si tiene buen color, si su piel está sana, elástica, firme y caliente, sobre todo en las extremidades. 
$4^{\circ} \mathrm{Si}$ está siempre alegre, con apetito y si obra bien.

\section{Alimentación}

¡Alimente Ud. a su niño al pecho! Toda madre puede $\mathbf{y}$ debe amamantar el mayor tiempo posible a su niño. Así le evitará las enfermedades intestinales que son inmensamente más frecuentes y más graves en los niños alimentados artificialmente.

El niño tiene derecho a la leche de su madre y la lactancia no trae ningún mal para la mujer que cría. Sólo la tuberculosis, las enfermedades graves del corazón y de los riñones y algunas enfermedades contagiosas obligan a quitar el pecho. Los dolores de espalda u otras ligeras molestias como la sensación de debilidad general no son motivos para suspender la crianza al pecho.

El embarazo o la menstruación producen algunas veces ligero malestar al niño, pero tampoco son una razón para destetar al niño.

El pecho se dará cada 3 horas o cada 3 horas y media y no más de un 1/4 de hora.

Si la leche falta por completo habrá de recurrir a la leche de vaca. Antes de decidirse a este cambio de régimen que es siempre peligroso, consulte en la Gota de Leche, en el consultorio de lactantes de los hospitales o a su médico particular, para que se le indique la mejor forma de empezar la alimentación.

La leche de vaca debe reunir las siguientes condiciones:

$1^{\circ}$ Ser pura, de vacas sanas, ordeñadas con todo aseo y recibida en recipientes limpios, sin saltaduras.

$2^{\circ}$ Debe ser hervida inmediatamente después de ordeñada y sólo durante 2 ó 3 minutos y enfriada lo más rápidamente que se pueda y guardada en lugar fresco, si es posible, en el hielo o agua helada.

$3^{\circ}$ No debe volverse a hervir sino que se la entibiará al baño maría a tiempo de dar la mamadera.

En general se dará el pecho por poca leche que se tenga y se enterará la ración con leche de vaca, sobre todo a las horas en que el pecho da menos leche, o sea en la tarde.

A los 3 meses dar 5 cucharadas de leche, tres de agua de arroz o quáker y 1 terrón y medio de azúcar

A los 5 meses, 7 cucharadas de leche y 1 cucharadita de maicena o harina tostada, cocida cinco minutos en 4 cucharadas de agua con 1 terrón y medio de azúcar

A los 6 meses, empezar poquito a poco a dar sopa de arroz o sémola, en caldo de verduras comenzando por una cucharada dos veces y aumentando poco a poco hasta dar un plato dos veces al día.

Se dará entonces alimento cada 4 horas y se comenzará a agregar puré de verduras o legumbres (espinacas, acelgas, zanahorias, coliflor papas, zapallo, camote, arvejas, lentejas, garbanzos, porotos) con mantequilla, aumentando muy poco a poco esa cantidad.

$\mathrm{Al}$ año y medio puede dársele huevos y carne molida, sesos o hígado molido, frutas crudas y molidas o ralladas.

Evitar las galletas, dulces, golosinas. ¡¡Jamás una gota de licor!!

A los dos años el niño puede comer los guisos corrientes.

No dar nunca a un niño más de $1 / 2$ de litro de leche al día. Es preferible agregar desde temprano otros alimentos como queda dicho anteriormente.

Si el niño tiene diarrea o vómitos no emplee purgantes ni desinfectantes: mientras llama al médico, suprima todo alimento durante 12 ó 24 horas y no dé al niño sino agua pura o agua de té simple en abundancia y sin azúcar.

Cuando el niño tenga ya dientes, límpieselos dos o tres veces a día. Quitando todo el resto de comida que quede adherido a ellos, no se picarán, es decir, no tendrán caries y se evitará que el niño sufra graves enfermedades de la boca, del cuello, de las glándulas o se perjudiquen en su desarrollo.

¡iDentadura sana significa salud, buen desarrollo, buena digestión!!

\section{Comentario}

La pediatría surgió como especialidad en Europa a fines del siglo XIX. Giuseppe Mazzini se refiere a los inicios de la Pediatría en nuestro país en un artículo publicado el año 1934: “En 
mis tiempos -hace, como digo, treinta añoscasi no se hablaba, en Chile, de pediatría. El ilustre y malogrado profesor, don Roberto del Río - a quien recuerdo como clínico de valor, entusiasta y tenaz en su apostolado a favor de los niños desvalidos- era el único, quizás, que preveía y se daba cuenta de la importancia que la pediatría llegaría a tener entre las otras especialidades de la ciencia médica" 3 .

La especialidad se desarrolló en forma importante durante el siglo XX, bajo el modelo de atención sanitaria basado en criterios científicos y con un enfoque sistémico; se priorizó la salud materno- infantil y el entorno del hogar, además de otras políticas sociales ${ }^{4}$.

En su clase inaugural del curso de Pediatría del año 1934, el Dr. Anibal Ariztía se refiere al rol higienista preventivo del pediatra y nos advierte sobre el riesgo de la subespecialización ${ }^{5}$ : "Estas reflexiones me han inducido a destinar esta disertación a hacer un comentario sobre las nuevas condiciones que un pediatra moderno encuentra en sus estudios y en el ejercicio profesional, derivadas por una parte de la actual organización social y por otra de los adelantos de la Pediatría Científica.

... Si comparamos el rol desempeñado por el médico de hace 20 a 25 años y sus cualidades con las de un médico moderno, vemos que el colega de antes podía con acierto y con la aprobación de todos, ejercer sus actividades en campos que se encuentran ahora perfectamente delimitados y separados en especialidades por fronteras que hoy día impiden sean desempeñadas honrosamente por un mismo individuo. Esas circunstancias permitían al médico llegar a ser en el seno de las familias no sólo el que curaba las enfermedades sino también el consejero y director en todos los asuntos referentes a la salud de los padres y los hijos, en los conflictos y problemas psicológicos y pedagógicos de estos, etc, con lo cual ejercitaba y ampliaba su criterio clínico que tanto admiramos en los tratadistas clásicos de antaño. Esa condición de "médico de familia" tiende cada día a hacerse más rara, por desgracia o por felicidad, según el criterio con que se considere, a medida que avanza el perfeccionamiento médico.
...Aún antes de plantearse claramente y resolverse las cuestiones relativas a la biología del niño y su desarrollo y, en consecuencia, las características especiales de su patología, empezó a preocupar la atención de médicos y sociólogos la gravedad representada por las altas cifras de mortalidad infantil y la necesidad de arbitrar nuevas medidas para combatirla en vista de la insuficiencia de los recursos ofrecidos por la medicina individual curativa."

El Dr. Calvo Mackenna, a fines de los años 20 evidenció la importancia de acercar la atención de salud a la comunidad y de la educación sanitaria para el progreso y superación de las altas tasas de mortalidad infantil ${ }^{6}$. Ya desde entonces la puericultura ocupaba un importante lugar en la actividad de los pediatras. "con la experiencia adquirida durante más de 20 años de contacto con las madres del pueblo en policlínicos de primera infancia, consultorios de lactantes, gotas de leche, asilos maternales, orfelinatos, etc., nos creemos autorizados para sostener que el medio verdaderamente eficaz de vulgarización de la higiene infantil es la enfermera visitadora de puericultura, competente, asidua y bondadosa, la cual, enviada al domicilio del niño, periódica y frecuentemente, por el consultorio de lactantes de la gota de leche, a cuyo personal técnico pertenece, establece en cada uno de los domicilios una cátedra de enseñanza práctica en donde vigila y colabora en la ejecución de los consejos que el personal médico formuló en el consultorio y allí educa a la madre en cada detalle de higiene personal o colectiva de la familia, atiende los detalles del tratamiento de las enfermedades $y$, ante todo, hace profilaxia eminentemente práctica, estimulando la lactancia materna, haciendo ver los peligros del biberón, cooperando en la preparación, dosificación y administración de las mezclas de leche de vaca, etc."

El Patronato Nacional de la Infancia a través de las Gotas de Leche cumplió un rol fundamental en la educación sanitaria, priorizando las acciones preventivas y protección de la salud infantil ${ }^{7}$. Según refiere el Dr. Ariztía ${ }^{5}$, estas instituciones se basaron en el modelo propuesto por el Profesor Budin de París, quien, 
"impresionado por el desperdicio de esfuerzos y vidas que significaba la alta mortalidad de los lactantes de mujeres atendidas en su maternidad, ideó y creó en 1892 "Les consultations de nourrissons", cuyo esquema ha servido de modelo a todos los Consultorios de lactantes de las instituciones de asistencia maternal e infantil en todas partes del mundo, incluso las Gotas de Leche creadas por Dufour, por la vez primera en 1893 en Fécamp. En ellos no se persigue la curación de enfermedades producidas, sino la instrucción y educación de las madres en la dietética y cuidados de su hijo, en la prevención de las enfermedades corrientes en la lactancia, etc."

Gracias a los progresos socio sanitarios el objetivo de la pediatría ha ido modificándose en congruencia con los cambios sociodemográficos, la revolución científica tecnológica, los cambios socio-políticos, culturales y económicos, junto al fenómeno de la globalización y el acceso universal a la información, determinando nuevos desafíos y roles para los pediatras ${ }^{8}$.

Como consecuencia de esta transición, pasamos del predominio de las enfermedades infectocontagiosas y la desnutrición, a la denominada morbilidad del milenio, que incorpora aspectos familiares, sociales y educacionales ${ }^{9}$.

Frente a la nueva morbilidad, el pediatra, ha recuperado su rol de consejero y educador. El “cultivo de los niños” o la puericultura, ha vuelto a adquirir un rol central en los cuidados de la infancia, tal como se mencionaba en los artículos de hace 75 años.

\section{Referencias}

1.- Diccionario de la Real Academia Española. [Accedido 22 agosto 2007]. Disponible en http://buscon.rae.es/ draeI/

2.- Actividad de La Semana de la Madre. Rev Chil Pediatr 1930; 1 (1): 51-3.

3.- Mazzini G: Algo sobre Nipiologia. Rev Chil Pediatr 1934; 5 (5): 237-44.

4.- Jiménez J, Romero MI: Reducción de la mortalidad infantil en Chile: un éxito en dos etapas. Rev Panam Salud Pública 2007; 21 (4): 251-3. [accedido 21 Agosto 2007] disponible en http://journal.paho.org/ index.php?a_ID=910

5.- Ariztía A: Sobre orientaciones actuales de la enseñanza de la pediatría. (Lección inaugural del curso extraordinario de Pediatría). Rev Chil Pediatr 1934; 5 (4): $169-86$.

6.- Calvo Mackenna L: La mortalidad infantil en Chile, estudiada por la Sociedad de las Naciones (III). Rev Chil Pediatr 1930; 1 (8): 411-23.

7.- Vargas $N$ : Historia de la pediatría chilena: crónica de una alegría. Editorial Universitaria. Santiago de Chile 2002.

8.- Jiménez de la Jara J: Atención pediátrica y sistemas de salud en Chile. Rev Chil Pediatr 2000; 71 (5): 3779.

9.- Palfrey J, Tonniges T, et al: Addressing the Millennial Morbidity-The Context of Community Pediatrics. Pediatrics 2005; 115 (4): 1121-3. 